\title{
MicroRNA-1185 Promotes Arterial Stiffness though Modulating VCAM-1 and E-Selectin Expression
}

\author{
Haoyuan Deng ${ }^{\mathrm{a}}$ Zhenfeng Song ${ }^{\mathrm{a}}$ Huan $\mathrm{Xu}^{\mathrm{a}} \quad$ Xinrui Deng $^{\mathrm{a}}$ Qiao Zhang ${ }^{\mathrm{a}}$ \\ Hongyu Chen ${ }^{a}$ Yanjiao Wang ${ }^{a}$ Ying Qin ${ }^{a}$ Ying Lia,b \\ aDepartment of Nutrition and Food Hygiene, Public Health College, Harbin Medical University, Harbin, \\ ${ }^{b}$ Research Institute of Food, Nutrition and Health, Sino-Russian Medical Research Center, Harbin \\ Medical University, Harbin, China
}

\section{Key Words}

miR-1185 • Arterial stiffness • Adhesion molecules • Atherosclerosis

\begin{abstract}
Background/Aims: Atherosclerosis is the primary cause of cardiovascular ischaemic events; arterial stiffness is a characteristic of the atherosclerotic process. MicroRNAs (miRNAs) have been revealed as crucial modulators of atherosclerosis. However, the role of arterial stiffnessrelated miRNAs in the atherosclerotic process is still unclear. Methods: Four hundred six participants from Northern China were enrolled in this study. Circulating miR-1185 and adhesion molecule levels were measured. Multiple linear regression models were used to evaluate the association of miR-1185 levels with brachial-ankle pulse wave velocity (baPWV) and adhesion molecule levels. A mediation analysis was also performed to examine the mediating effect. Cell adhesion molecule levels were measured in primary human umbilical vein endothelial cells (pHUVECs) and human umbilical vein smooth cells (HUVSMCs) transfected with miR-1185 or co-transfected with a miR-1185 inhibitor. Results: miR-1185 was independently correlated with arterial stiffness. A positive relationship between miR-1185 and vascular cell adhesion molecule-1 (VCAM-1) and E-selectin levels was observed. VCAM1 and E-selectin partially mediated the correlation between miR-1185 and arterial stiffness. miR-1185 induced a significant increase in the VCAM-1 and E-selectin levels in pHUVECs and HUVSMCs in vitro. According to our mechanistic analysis, VCAM-1 and E-selectin mediated miR-1185-induced arterial stiffening. Conclusions: miR-1185 modulated the expression of VCAM- 1 and E-selectin to promote arterial stiffening, suggesting that miR-1185 plays a crucial role in the development of atherosclerosis and may serve as a novel therapeutic target for atherosclerosis.

\section{Introduction}

Atherosclerosis, which is the main cause leading to myocardial and cerebral infarction, is responsible for the mortality rate of cardiovascular diseases (CVD) [1]. Although the 
process by which atherosclerosis develops is complex, arterial stiffness plays a crucial role in the process. In fact, arterial stiffness is increased in subjects with CVD [2,3], which has been suggested to be a potential marker and predictor of atherosclerosis [4-6]. Because the association between arterial stiffness and atherosclerosis has been well established, the cause of arterial stiffening is gaining more attention. Several studies have revealed the characteristics of arterial stiffness, which include increased intima-media thickness, endothelial dysfunction, increased collagen production and elastin degradation $[7,8]$. Although some mechanisms that are conducive to arterial stiffness increased have been suggested in previous studies [9-12], the mechanisms underlying arterial stiffening require further elucidation.

MicroRNAs (miRNAs) are small, non-coding RNAs that regulate target genes though degradation or the inhibition of post-transcriptional gene expression [13]. miRNAs are stably expressed in the circulatory system and are detected in the plasma, serum, platelets and nucleated blood cells $[14,15]$. Recently, roles for miRNAs in the pathological and physiological processes of CVD, such as atherosclerosis, have been suggested [16-24]. Furthermore, accumulating evidence has indicated potential roles for miRNAs in endothelial function, angiogenesis and vascular remodelling [25-28]. However, the modulatory effects of miRNAs on arterial stiffness are still unclear.

Adhesion molecules, which are expressed in the endothelium, have been shown to mediate the process of monocyte recruitment [29], a characteristic of the early phase of atherosclerosis [30,31]. Adhesion molecules are expressed in early atherosclerotic lesions $[32,33]$, and soluble adhesion molecules are considered risk predictors for cardiovascular events [34]. Furthermore, aberrant expression levels of adhesion molecules play crucial roles in arterial stiffness [35].

As shown in our previous study, miR-1185 induces endothelial dysfunction (unpublished data). Thus, the primary aim of this study was to determine whether the effect of miR1185 on arterial stiffness could be mediated by adhesion molecules. We first examined the association between miR-1185 and arterial stiffness and adhesion molecule expression in a cross-sectional study to verify the effect of miR-1185 on arterial stiffness. Furthermore, we performed cellular experiments in two types of cells, primary human umbilical vein endothelial cells (pHUVECs) and human umbilical vein smooth muscle cells (HUVSMCs), to examine the effect of miR-1185 on the expression of adhesion molecules.

\section{Materials and Methods}

\section{Study population}

The Harbin Cohort Study on Diet, Nutrition and Chronic Noncommunicable Disease (HDNNCDS) was used in our study. The study design and recruitment of participants have been described previously [36]. In this study, participants with hepatitis, nephropathy, hormone therapy, taking medication for inflammatory or metabolic disorders or with missing data were excluded. Four hundred six participants were randomly selected from 8,142 eligible participants for enrolment in this study. The Ethical Committee of Harbin Medical University approved the study protocol, and written informed consent was obtained from all participants.

\section{Anthropometric measurements}

Participants' heights and body weights were measured when they were wearing light, thin clothing and no shoes. Body weights and heights were measured to the nearest $0.1 \mathrm{~kg}$ and $0.1 \mathrm{~cm}$, respectively. Each participant's blood pressure was measured 3 times using a standard mercury sphygmomanometer placed on the right arm after 10-min of rest in a seated position, and the mean values were used for the analysis. Body mass index (BMI) was calculated as weight $(\mathrm{kg})$ divided by the squared height in metres $\left(\mathrm{m}^{2}\right)[36]$.

Biochemical analyses

Fasting blood glucose and 2-h glucose levels were measured using an automatic biochemistry analyser (Hitachi 7100, Tokyo, Japan). Serum vascular cell adhesion molecule-1 (VCAM-1), intercellular cell adhesion 


\section{Cellular Physiology Cell Physiol Biochem 2017;41:2183-2193 \begin{tabular}{ll|l} 
and Biochemistry & $\begin{array}{l}\text { DOI: 10.1159/000475576 } \\
\text { Published onIIne: AprII L1, } 2017\end{array}$ & $\begin{array}{l}\text { C } 2017 \text { The Author(s). Published by S. Karger AG, Basel } \\
\text { www.karger.com/cpb }\end{array}$ \\
\hline
\end{tabular} \\ Deng et al.: miR-1185 Modulates Arterial Stiffness}

molecule-1 (ICAM-1) and E-selectin levels were measured with enzyme-linked immunosorbent assay (ELISA) kit (Cusabio, Wuhan, China) according to the manufacturer's instructions.

Assessment of brachial-ankle pulse wave velocity (baPWV)

Participants' baPWVs were measured after a 10-min rest in the supine position by well-trained examiners using an automated waveform analyser (Colin VP1000, Ormon, Japan). The participants were asked to wear loose clothing and no shoes when the measurements were performed. The mean baPWV from the measurements obtained on the left and right sides were used for the analysis.

\section{Outcomes}

Diabetes was defined as fasting blood glucose levels $\geq 7.0 \mathrm{mmol} / \mathrm{L}$ or 2 -h glucose levels $\geq 11.0 \mathrm{mmol} / \mathrm{L}$. Hypertension was defined as systolic blood pressure (SBP) $\geq 140 \mathrm{mmHg}$ or diastolic blood pressure (DBP) $\geq 90 \mathrm{mmHg}$.

Cell culture and transfection

The pHUVECs were obtained from AllCells (Shanghai, China) and cultured in complete medium (AllCells, Shanghai, China). The HUVSMCs were purchased from ScienCell (Carlsbad, CA, USA) and cultured in basal medium (ScienCell, Carlsbad, CA, USA) with smooth muscle cell growth supplement (ScienCell) and $10 \%$ FBS (PAA Laboratories, Pasching, Austria). The cells were cultured at $37^{\circ} \mathrm{C}$ in a $5 \% \mathrm{CO}_{2}$ and $95 \%$ air atmosphere.

All cells (pHUVECs and HUVSMCs) were transfected with 50 nM miR-1185 mimic (RiboBio Co., Guangzhou, China) or co-transfected with 50 nM miR-1185 and 100 nM miR-1185 inhibitor (RiboBio Co., Guangzhou, China) with the Lipofectamine 2000 reagent (Invitrogen, Carlsbad, USA) according to the manufacturer's protocol. A scrambled sequence was used as a negative control (NC). Forty-eight hours after transfection, the cells were used for the subsequent experiments.

\section{RNA isolation and real-time quantitative polymerase chain reaction ( $q R T-P C R$ )}

miR-1185 was extracted from the plasma using an miRNeasy RNA Isolation Kit (Qiagen, Hilden, Germany), and the expression levels were normalized to U6 expression according to the manufacturer's protocol. Primers (miR-1185 and U6) were purchased from Qiagen.

For the mRNA assessment, total RNA was isolated from the pHUVECs and HUVSMCs using TRIzol reagent (Invitrogen) according to the manufacturer's instructions, and $\beta$-actin expression was used as an internal control. Primers (VCAM-1, ICAM-1, E-selectin, and $\beta$-actin) were synthesized by Invitrogen. Primer sequences are listed in Table 1. Real-time PCR was performed with the SYBR Green PCR Master Mix (Applied Biosystems, Foster City, CA, USA) [37].

Immunofluorescence staining

Cells (pHUVECs and HUVSMCs) were washed with PBS and fixed with 4\% paraformaldehyde. Cells (pHUVECs and HUVSMCs) were incubated with a fluorescein isothiocyanate (FITC)-conjugated VCAM-1 antibody (BD, Franklin Lakes, NJ, USA) for $30 \mathrm{~min}$, and then the cell nuclei were counterstained with DAPI (Beyotime Biotechnology, Jiangsu, China) for $15 \mathrm{~min}$. The fluorescent signal was detected with a confocal microscope (Nikon, Tokyo, Japan).

Table 1. Primer sequences used for real-time PCR

\begin{tabular}{lll}
\hline Gene & \multicolumn{2}{l}{ Primer sequence } \\
\hline VCAM-1 & Sense & 5'-TTCCCTAGAGATCCAGAAATCGAG-3' \\
& Antisense & 5'-CTTGCAGCTTACAGTGACAGAGC-3' \\
ICAM-1 & Sense & 5'-CTCCAATGTGCCAGGCTTG-3' \\
& Antisense & 5'-CAGTGGGAAAGTGCCATCCT-3' \\
\multirow{2}{*}{ E-selectin } & Sense & 5'-TGAAGCTCCCACTGAGTCCAA-3' \\
& Antisense & 5'-GGTGCTAATGTCAGGAGGGAGA-3' \\
\multirow{2}{*}{-actin } & Sense & 5'-ACTATCGGCAATGAGCG-3' \\
& Antisense & 5'-GAGCCAGGGCAGTAATCT-3' \\
\hline
\end{tabular}




\section{Cellular Physiology Cell Physiol Biochem 2017;41:2183-2193 \begin{tabular}{l|l} 
and Biochemistry Published on/Ine: April 21, 2017 & $\begin{array}{l}\text { C } 2017 \text { The Author(s). Published by S. Karger AG, Basel } \\
\text { www.karger.com/cpb }\end{array}$ \\
\hline
\end{tabular}

\section{Statistical analysis}

Data are presented as means \pm standard deviations (SD) and medians (interquartile ranges) for the continuous variables with normal and skewed distributions and frequencies for the categorical variables. Participants were stratified into low and high miR-1185 groups based on their median circulating miR1185 levels. Continuous variables were compared using $t$-tests, and chi-square tests were used to compare the categorical data between two groups. Normal distributions were obtained after log transformation of the circulating miR-1185 levels, and the transformed data were used for the subsequent analysis. Multiple linear regression models were performed; Model 1 was performed without covariates, and Model 2 was adjusted for age, sex, BMI, smoking rate and alcohol consumption rate. A mediation model was constructed to examine whether the association between miR-1185 and baPWV was mediated by VCAM-1 and E-selectin after adjusting for age, sex, BMI, smoking rate and alcohol consumption rate. miR-1185 was the predictor variable (X), VCAM-1 and E-selectin were the mediators (M1 and M2), and baPWV was the outcome variable (Y). Four steps were conducted in the mediation analysis: 1) examining the association between the predictor variable and outcome (Model $\left.\mathrm{Y}=\beta_{\mathrm{Tot}} \mathrm{X}\right)\left(\beta_{\mathrm{Tot}}=\right.$ total effect); 2 ) examining the association between the predictor variable and mediators (Model M1 $=\beta_{1} \mathrm{X}$; Model M2 $\left.=\beta_{2} \mathrm{X}\right)\left(\beta_{1}=\right.$ indirect effect $1 ; \beta_{2}=$ indirect effect 2); 3 ) examining the association between the mediators and outcome variable while controlling for the predictor (Model $\left.Y=\beta_{3} \mathrm{M} 1+\beta_{4} \mathrm{M} 2+\beta_{\operatorname{dir}} \mathrm{X}\right)\left(\beta_{3}=\right.$ indirect effect $3 ; \beta_{4}=$ indirect effect $4 ; \beta_{\text {dir }}=$ direct effect); and 4) calculating the percentage of mediation: mediation effect for M1 $(\%)=\left(\beta_{1} \times \beta_{3} / \beta_{\text {Tot }}\right) \times 100 \%$ and mediation effect for M2 $(\%)=\left(\beta_{2} \times \beta_{4} / \beta_{\text {Tot }}\right) \times 100 \%$. A mediation analysis was performed using structural equation modelling (SEM) and a path diagram analysis with IBM SPSS Amos as described in a previous study [38].

For the cell-based experiments, the values are shown as the means \pm SD obtained from at least three separate experiments. Significance was determined using one-way ANOVA followed by the StudentNewman-Keuls (SNK) test.

SPSS v20.0 (Chicago, IL, USA) was used for all statistical analysis. A two-sided $P$-value $<0.05$ was considered statistically significant.

\section{Results}

Characteristics of the participants according to their circulating miR-1185 levels

Compared with participants in the low miR-1185 group, participants in the high miR1185 group were significantly older and exhibited markedly increased baPWV and VCAM-1 and E-selectin levels. A significant difference in the prevalence of hypertension between the two groups was observed (Table 2).

Table 2. Characteristics of the low and high circulating miR-1185 groups. The data are presented as the means \pm SD or medians (interquartile ranges) for continuous variables or frequencies for categorical variables. BMI: body mass index; baPWV: brachial-ankle pulse wave velocity; VCAM-1: vascular cell adhesion molecule-1; ICAM-1: intercellular cell adhesion molecule-1. Diabetes was defined as fasting blood glucose levels $\geq 7.0 \mathrm{mmol} / \mathrm{L}$ or 2-h glucose levels $\geq 11.0 \mathrm{mmol} / \mathrm{L}$. Hypertension was defined as systolic blood pressure $(\mathrm{SBP}) \geq 140 \mathrm{mmHg}$ or diastolic blood pressure (DBP) $\geq 90 \mathrm{mmHg}$

\begin{tabular}{lllc}
\hline Variable & Low Group & High Group & $P$ value \\
\hline miR-1185 levels & $0.13(0.03,0.48)$ & $4.44(2.02,9.02)$ & \\
Age $(y)$ & $53.27 \pm 7.76$ & $55.07 \pm 7.56$ & 0.018 \\
Male $(\%)$ & 27.09 & 25.12 & 0.735 \\
BMI $\left(\mathrm{kg} / \mathrm{m}^{2}\right)$ & $24.54 \pm 3.09$ & $25.10 \pm 3.31$ & 0.081 \\
baPWV $(\mathrm{cm} / \mathrm{s})$ & $1536.38 \pm 486.31$ & $1781.66 \pm 505.47$ & $<0.001$ \\
VCAM-1 $(\mathrm{ng} / \mathrm{ml})$ & $134.08 \pm 70.20$ & $152.95 \pm 92.43$ & 0.038 \\
ICAM-1 $(\mathrm{ng} / \mathrm{ml})$ & $241.80 \pm 155.92$ & $262.23 \pm 173.83$ & 0.259 \\
E-selectin $(\mathrm{ng} / \mathrm{ml})$ & $52.17 \pm 20.37$ & $57.09 \pm 21.51$ & 0.031 \\
Smoking rate $(\%)$ & 16.26 & 13.30 & 0.484 \\
Alochol consumption rate $(\%)$ & 32.54 & 31.53 & 0.830 \\
Diabetes $(\%)$ & 23.16 & 27.58 & 0.362 \\
Hypertension $(\%)$ & 45.32 & 62.56 & $<0.001$ \\
\hline
\end{tabular}


Table 3. Relationship between circulating miR-1185 levels and baPWV and adhesion molecule expression. $\beta$ represents the standard coefficient. Model 1 was crude; Model 2 was adjusted for age, sex, BMI, smoking rate, and alcohol consumption rate. baPWV: brachial-ankle pulse wave velocity; VCAM-1: vascular cell adhesion molecule-1; ICAM-1: intercellular cell adhesion molecule-1

\begin{tabular}{|c|c|c|c|c|c|c|c|c|}
\hline \multirow{2}{*}{\multicolumn{3}{|c|}{$\begin{array}{r}\text { Relationship between circula } \\
\text { baPWV }(\mathrm{cm} / \mathrm{s}) \\
\beta \quad P \text { value }\end{array}$}} & \multicolumn{2}{|c|}{ VCAM-1 (ng/ml) } & \multicolumn{2}{|c|}{ ICAM-1 (ng/ml) } & \multicolumn{2}{|c|}{ E-selectin (ng/ml) } \\
\hline & & & $\beta$ & $P$ value & $\beta$ & $P$ value & $\beta$ & $P$ value \\
\hline Model 1 & 0.407 & $<0.001$ & 0.224 & $<0.001$ & 0.013 & 0.811 & 0.234 & $<0.001$ \\
\hline Model 2 & 0.284 & $<0.001$ & 0.174 & 0.001 & 0.007 & 0.903 & 0.152 & 0.002 \\
\hline
\end{tabular}

Table 4. Associations of adhesion molecule levels with baPWV. $\beta$ represents the standard coefficient. Model 1 was crude; Model 2 was adjusted for age, sex, BMI, smoking rate, and alcohol consumption rate. VCAM-1: vascular cell adhesion molecule-1; ICAM-1: intercellu-

\begin{tabular}{lcrcr}
\hline \multirow{2}{*}{ Variable } & \multicolumn{2}{c}{ Model 1 } & \multicolumn{2}{c}{ Model 2 } \\
& $\beta$ & $P$ value & $\beta$ & $P$ value \\
\hline VCAM-1 $(\mathrm{ng} / \mathrm{ml})$ & 0.364 & $<0.001$ & 0.258 & 0.001 \\
ICAM-1 $(\mathrm{ng} / \mathrm{ml})$ & 0.134 & 0.014 & 0.134 & 0.005 \\
E-selecin $(\mathrm{ng} / \mathrm{ml})$ & 0.475 & $<0.001$ & 0.322 & $<0.001$ \\
\hline
\end{tabular}
lar cell adhesion molecule-1

Fig. 1. Mediating effects of VCAMbetween miR-1185 and baPWV. Structural equation modelling was used after adjusting for age, sex, BMI, smoking rate and alcohol consumption rate. $\beta$ represents the standard regression coefficient. ${ }^{*} P<0.05,{ }^{* *} P<0.001$. 1 and E-selectin on the association

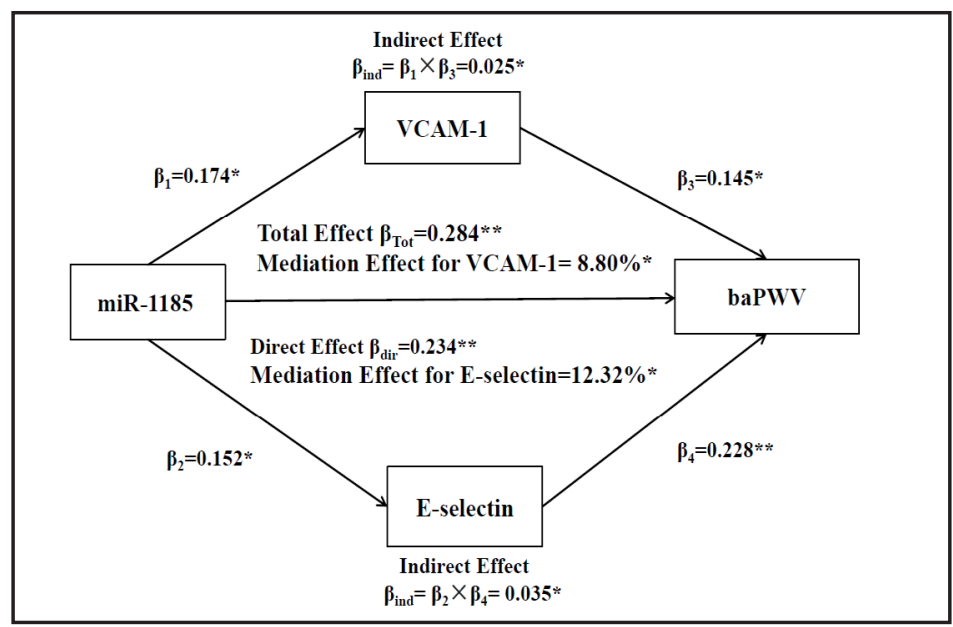

Association between the circulating miR-1185 levels and baPWV and adhesion molecule levels

A significant positive correlation between miR-1185 levels and baPWV $(P<0.001)$, VCAM-1 $(P<0.001)$ and E-selectin $(P<0.001)$ in Model 1 was observed. In the multiple linear regression models, Model 2 revealed a positive correlation between the miR-1185 levels and baPWV $(P<0.001)$ and VCAM-1 $(P=0.001)$ and E-selectin levels $(P=0.002)$ after adjusting for age, sex, BMI, smoking rate and alcohol consumption rate. However, a significant correlation between the miR-1185 and ICAM-1 levels was not observed (Table 3).

\section{Relationship between adhesion molecule levels and baPWV}

In Model 1 adhesion molecules, including VCAM-1 $(P<0.001)$, ICAM-1 $(P=0.014)$ and E-selectin $(P<0.001)$ levels resulted positively associated with baPWV. Based on multiple linear regression Model 2, the levels of the adhesion molecules VCAM-1 $(P=0.001)$, ICAM$1(P=0.005)$, and E-selectin $(P<0.001)$ were significantly associated with baPWV after adjusting for age, sex, BMI, smoking rate and alcohol consumption rate (Table 4).

Direct and indirect effects of miR-1185 on baPWV

As shown in Figure 1, the total effect of miR-1185 on baPWV, which was measured as a standardized regression coefficient $\left(\beta_{\mathrm{Tot}}=0.284 ; P<0.001\right)$, was estimated without VCAM-1 
Fig. 2. $\operatorname{miR}-1185$ regulates adhesion a molecule expression in pHUVECs. The expression of the VCAM-1 (a), E-selectin (b), and ICAM-1 mRNA (c), and immunofluorescence analysis (scale bar, $50 \mu \mathrm{m}$ ) of VCAM-1 protein expression (d) in the pHUVECs treated with different transfection are shown. The pHUVECs were transfected with miR-1185 mimic or co-transfected with miR-1185 inhibitor. The scrambled sequence was used as a negative control (NC). ${ }^{*} P<$ 0.05 and ${ }^{* *} P<0.01$ for the indicated comparisons.

\section{a}

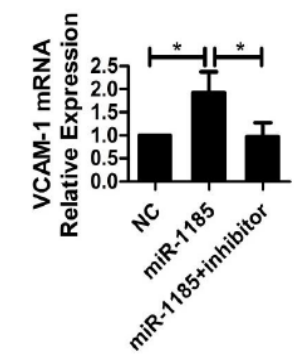

d

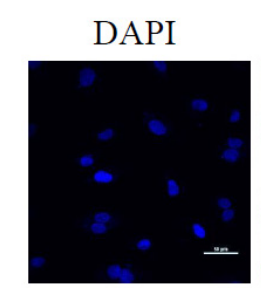

b

c
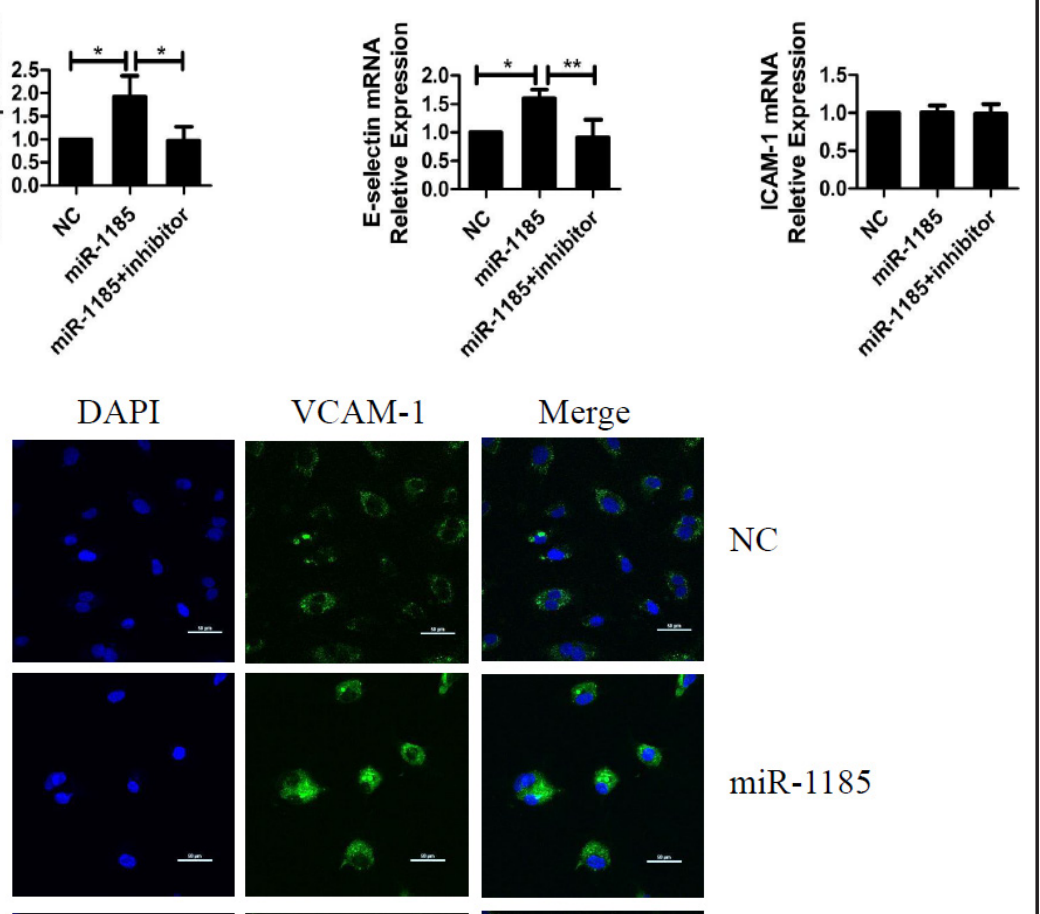

$\mathrm{NC}$
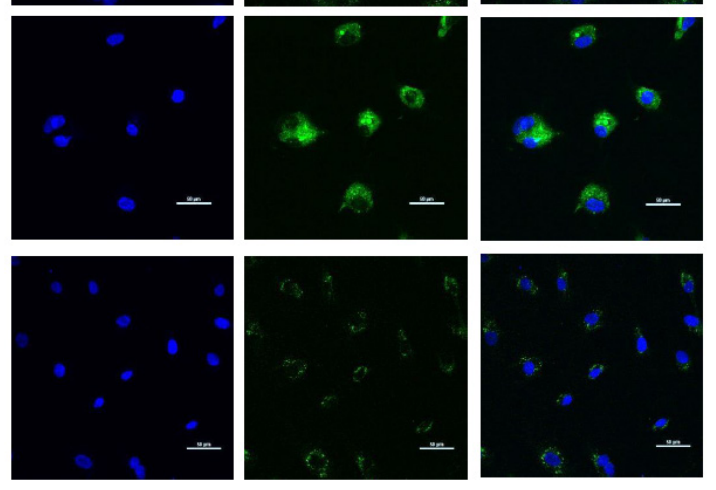

miR-1185+inhibitor

and E-selectin in the model. The $\beta 1$ to $\beta 4$ values were used to calculate the overall indirect effects of VCAM-1 and E-selectin, respectively $\left(\beta_{\text {ind }}=0.025\right.$ for VCAM- 1 and $\beta_{\text {ind }}=0.035$ for E-selectin; both $P<0.05)$. The percentages of the total effects mediated by VCAM-1 and E-selectin were estimated to be $8.80 \%$ and $12.32 \%$ (both $P<0.05$ ).

\section{miR-1185 modulated adhesion molecule expression in pHUVECs}

We examined the effect of miR-1185 on adhesion molecule expression in pHUVECs to assess the potential effect of miR-1185 on end othelial cell dysfunction. Cells transfected with miR-1185 exhibited a significant increase in the expression of the VCAM-1 mRNA, but cotransfection with the miR-1185 inhibitor eliminated this increase (Fig. 2a). The expression of the E-selectin mRNA was increased in pHUVECs transfected with miR-1185 compared with that in the NC group, whereas co-transfection with the miR-1185 inhibitor reversed the effect (Fig. 2b). miR-1185 did not significantly affect the expression of the ICAM-1 mRNA (Fig. 2c). Additionally, we examined the effect of miR-1185 on the accumulation of the VCAM-1 protein using immunofluorescence staining. The miR-1185-transfected pHUVECs exhibited a marked increase in the levels of the VCAM-1 protein compared with the levels in the NC group, and co-transfection with the miR-1185 inhibitor almost completely reversed the effect of miR-1185 (Fig. 2d).

miR-1185 modulated adhesion molecule expression in HUVSMCs

The effect of miR-1185 on adhesion molecule expression in HUVSMCs was detected. HUVSMCs transfected with miR-1185 exhibited a significant increase in the expression of the VCAM-1 and E-selectin mRNAs; however, co-transfection with the miR-1185 inhibitor 
Fig. 3. Effects of

miR-1185 on ad- a hesion molecule expression in the HUVSMCs. Changes in the expression of the VCAM-1 (a), E-selectin (b), and ICAM-1 mRNAs (c), as well as the accumulation of the VCAM-1 protein detected using immunofluorescence staining (scale bar, $50 \mu \mathrm{m})(\mathrm{d})$ in the HUVSMCs transfected with miR-1185 or co-transfected with miR-1185 inhibitor are shown. The scrambled sequence was used as a negative control (NC). ${ }^{*} P<0.05$ and ${ }^{* *} P<0.01$ for the indicated comparisons.

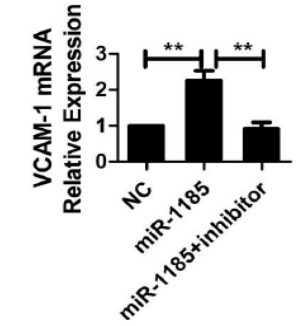

d
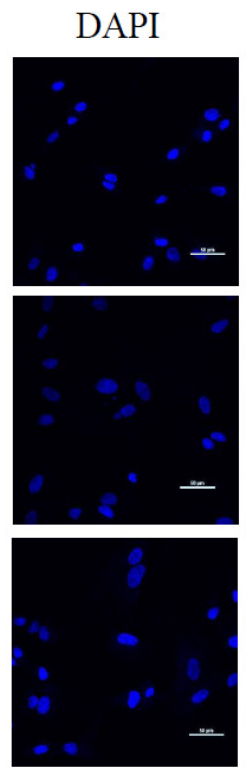

b

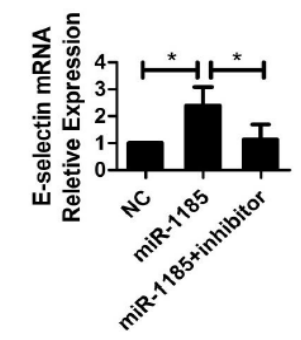

\section{VCAM-1}
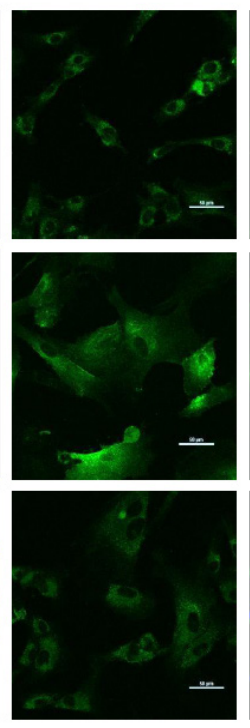

Merge c
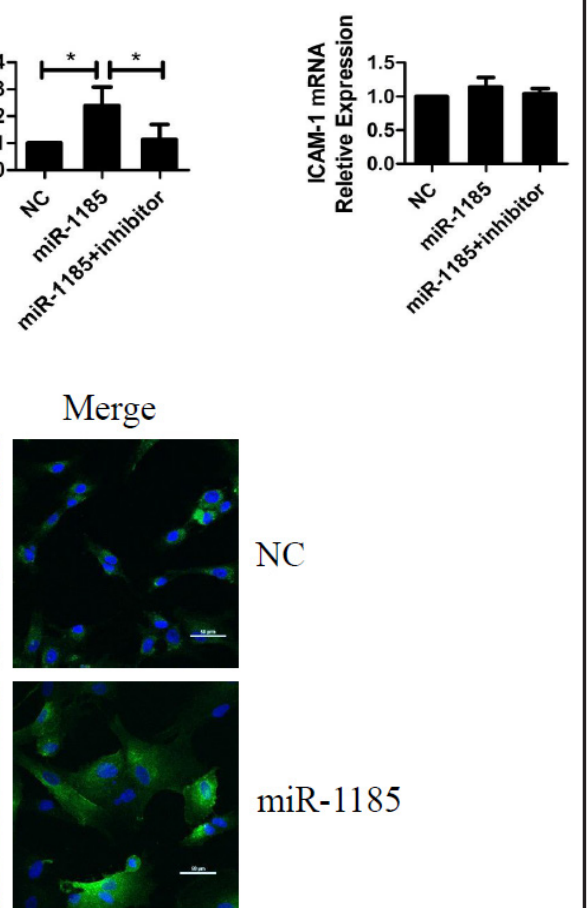

miR-1185

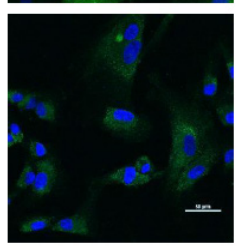

miR-1185+inhibitor

restored the mRNA levels (Fig. 3a and b). The levels of the ICAM-1 mRNA were not changed in HUVSMCs transfected with miR-1185 (Fig. 3c). The accumulation of VCAM-1 protein, which was measured using immunofluorescence staining, was dramatically increased in the miR-1185-transfected group, and co-transfection with the miR-1185 inhibitor significantly abrogated the effect of miR-1185 (Fig. 3d).

\section{Discussion}

As shown in the present study, miR-1185 plays a key role in the pathological and physiological processes of atherosclerosis. For the first time, we showed that miR-1185 was independently correlated with arterial stiffness. We also observed a positive correlation between miR-1185 and VCAM-1 and E-selectin levels. Furthermore, VCAM-1 and E-selectin partially mediated the relationship between miR-1185 and arterial stiffness. miR-1185 significantly induced the expression of VCAM-1 and E-selectin in pHUVECs and HUVSMCs in vitro. Thus, we conclude that miR-1185 may increase arterial stiffness by promoting VCAM-1 and E-selectin expression.

According to studies, vascular dysfunction is required to increase arterial stiffness [39-41]. In recent years, aberrant miRNA expression has been suggested to be involved in vascular dysfunction $[42,43]$. Specifically, miRNA-induced vascular dysfunction increased arterial stiffness in the study by Liao et al. [44]. Freedman et al. reported that miR-1185 was expressed at high levels in plasma and predicted to modulate both transcription factor expression and the cell cycle [45]. Importantly, we found that miR-1185 induced endothelial dysfunction in previous study (unpublished data). In this study, miR-1185 levels were 
positively associated with arterial stiffness. Thus, we proposed that increased miR-1185 levels lead to increased arterial stiffness.

Aberrant adhesion molecules have been considered characteristic for vascular dysfunction [46], and the modulatory effects of adhesion molecules on arterial stiffness have been explored. Arterial stiffness arises from a complex process involving structural alterations in the extracellular matrix (ECM) and changes in vascular tone [44]. Adhesion molecules have been shown to increase the arterial stiffness by participating in the remodelling of the ECM [35, 47]. The mediators of this process include matrix metalloproteinases (MMPs), which play a crucial role in the remodelling ECM, and adhesion molecules stimulate MMP activity and increase fragmentation of elastin molecules, a characteristic of arterial stiffness [47-49]. In addition to structural changes in the ECM, adhesion molecules also increase vascular tone. Vascular tone is directly modulated by factors regulating the smooth muscle layer or indirectly modulated by factors that regulate smooth muscle cells by stimulating the release of bioactive substances from endothelial cells [50]. The up-regulation of adhesion molecule expression in endothelial cells recruits circulating leukocytes to the vessel wall, which induces endothelial dysfunction and affects vascular tone [51,52]. Similarly, vascular smooth muscle cells also express adhesion molecules to guide migrating monocytes to the vessel wall [53]. Importantly, VCAM-1 has been shown to regulate the proliferation and migration of monocytes towards in smooth muscle cells [54]. In our study, we also identified a significant association between adhesion molecule levels and arterial stiffness.

Adhesion molecules can be regulated by pro-inflammatory cytokines, which activate nuclear factor- $\mathrm{\kappa B}$ and interferon regulatory factor-1 [55]. However, unknown factors that affect the stability of adhesion molecule mRNAs also modulate mRNA expression $[56,57]$. In this study, miR-1185 promoted the expression of VCAM-1 and E-selectin, suggesting the effect of miR-1185 on vascular dysfunction. The mechanism by which miR-1185 modulates adhesion molecule expression may include some currently unidentified target genes of miR-1185, which could regulate the signalling pathways related to the adhesion molecules, involved in the process. Nevertheless, the precise mechanism by which miR-1185 induced changes in VCAM-1 and E-selectin expression is still not completely understood.

To our knowledge, this study is the first to show that miR-1185 influences arterial stiffness by promoting VCAM-1 and E-selectin expression. Specifically, our study illustrates a novel mechanism by which arterial stiffness is increased: increased miR-1185 levels promote VCAM-1 and E-selectin expression, which induce endothelial dysfunction and lead to arterial stiffening and the development of atherosclerosis. Our findings contribute to the understanding of the pathogenesis of atherosclerosis and provide evidence that miR-1185 may be a promising therapeutic target and novel biomarker for atherosclerosis.

\section{Limitations}

Because species-specific miR-1185 was not expressed in mice and rats, we did not further explore the effect and mechanism of miR-1185-induced arterial stiffening in animal model. However, a cross-sectional design and different cell types, including pHUVECs and HUVSMCs, were used in this study to confirm the effect of miR-1185 on arterial stiffness and its related mechanisms. Our study reflects the effects of miR-1185 on arterial stiffness and the atherosclerotic process.

Another limitation is that all participants in this study were ethnic Chinese; therefore, further studies are needed to determine whether the relationship between miR-1185 levels and arterial stiffness can be extended to other ethnic groups.

\section{Acknowledgements}

This research was supported by grants from the National Natural Science Foundation of China (81472980, 81673153) and the Province in Heilongjiang Outstanding Youth Science Fund (JC201410). 


\section{Cellular Physiology Cell Physiol Biochem 2017;41:2183-2193 \begin{tabular}{ll|l} 
and Biochemistry Published online: April 21, 2017 & $\begin{array}{l}\text { C) } 2017 \text { The Author(s). Published by S. Karger AG, Basel } \\
\text { www.karger.com/cpb }\end{array}$ \\
\hline
\end{tabular} \\ Deng et al.: miR-1185 Modulates Arterial Stiffness}

\section{Disclosure Statement}

The authors declare no conflict of interests.

\section{References}

1 Ross R: The pathogenesis of atherosclerosis--an update. N Engl J Med 1986;314:488-500.

2 Hirai T, Sasayama S, Kawasaki T, Yagi S: Stiffness of systemic arteries in patients with myocardial infarction. A noninvasive method to predict severity of coronary atherosclerosis. Circulation 1989;80:78-86.

- 3 Gatzka CD, Cameron JD, Kingwell BA, Dart AM: Relation between coronary artery disease, aortic stiffness, and left ventricular structure in a population sample. Hypertension 1998;32:575-578.

4 Wilkinson IB, Cockcroft JR, Webb DJ: Pulse wave analysis and arterial stiffness. J Cardiovasc Pharmacol 1998;32:S33-37.

5 Cohn J: Vascular wall function as a risk marker for cardiovascular disease. J Hypertens Suppl 1999;17:S4144.

6 Laurent S, Boutouyrie P, Asmar R, Gautier I, Laloux B, Guize L, Ducimetiere P, Benetos A: Aortic stiffness is an independent predictor of all-cause and cardiovascular mortality in hypertensive patients. Hypertension 2001;37:1236-1241.

7 Virmani R, Avolio A, Mergner W, Robinowitz M, Herderick E, Cornhill J, Guo S, Liu T, Ou D, O'Rourke M: Effect of aging on aortic morphology in populations with high and low prevalence of hypertension and atherosclerosis. Comparison between occidental and Chinese communities. Am J Pathol 1991;139:1119. 1129.

8 Park S, Lakatta EG: Role of Inflammation in the Pathogenesis of Arterial Stiffness. Yonsei Med J 2012;53:258-261.

-9 Sakurai K, Cominacini L, Garbin U, Fratta PA, Sasaki N, Takuwa Y, Masaki T, Sawamura T: Induction of endothelin-1 production in endothelial cells via co-operative action between CD40 and lectin-like oxidized LDL receptor (LOX-1). J Cardiovasc Pharmacol 2004;44:S173-180.

10 Tanner FC, Noll G, Boulanger CM, Lüscher TF: Oxidized low density lipoproteins inhibit relaxations of porcine coronary arteries. Role of scavenger receptor and endothelium-derived nitric oxide. Circulation 1991;83:2012-2020.

11 Raychowdhury MK, Yukawa M, Collins LJ, Mcgrail SH, Kent KC, Ware JA: Alternative splicing produces a divergent cytoplasmic tail in the human endothelial thromboxane A2 receptor. J Biol Chem 1995;270:19256-19261.

12 Cracowski JL, Devillier P, Durand T, Stanke-Labesque F, Bessard G: Vascular biology of the isoprostanes. J Vasc Res 2001;38:93-103.

13 Nugent M: MicroRNA function and dysregulation in bone tumors: the evidence to date. Cancer Manag Res 2014;6:15-25.

14 Mitchell PS, Parkin RK, Kroh EM, Fritz BR, Wyman SK, Pogosovaagadjanyan EL, Peterson A, Noteboom J, O'Briant KC, Allen A: Circulating microRNAs as stable blood-based markers for cancer detection. Proc Natl Acad Sci U S A 2008;105:10513-10518.

15 Gilad S, Meiri E, Yogev Y, Benjamin S, Lebanony D, Yerushalmi N, Benjamin H, Kushnir M, Cholakh H, Melamed N: Serum MicroRNAs Are Promising Novel Biomarkers. PLoS One 2008;3:e3148.

-16 Raitoharju E, Lyytikäinen LP, Levula M, Oksala N, Mennander A, Tarkka M, Klopp N, Illig T, Kähönen M, Karhunen PJ: miR-21, miR-210, miR-34a, and miR-146a/b are up-regulated in human atherosclerotic plaques in the Tampere Vascular Study. Atherosclerosis 2011;219:211-217.

17 Jing C, Lin X, Qi H, Yang S, Zhang B, Hong J: MiR-17-5p as circulating biomarkers for the severity of coronary atherosclerosis in coronary artery disease. Int J Cardiol 2015;197:123-124.

18 Cengiz M, Yavuzer S, Kılıçkıran AB, Yürüyen M, Yavuzer H, Dikici SA, Karataş, Özen M, Uzun H, Öngen Z: Circulating miR-21 and eNOS in subclinical atherosclerosis in patients with hypertension. Clin Exp Hypertens 2015;37:643-649.

19 Huang YQ, Cai AP, Chen JY, Huang C, Li J, Feng YQ: The Relationship of Plasma miR-29a and Oxidized Low Density Lipoprotein with Atherosclerosis. Cell Physiol Biochem 2016;40:1521-1528. 


\section{Cellular Physiology Cell Physiol Biochem 2017;41:2183-2193 \begin{tabular}{l|l} 
DOI: 10.1159/000475576 & $\begin{array}{l}\text { O 2017 The Author(s). Published by S. Karger AG, Basel } \\
\text { www.karger.com/cpb }\end{array}$ \\
\hline
\end{tabular}

20 Wu HJ, Zhang CY, Zhang S, Chang M, Wang HY: Microarray Expression Profile of Circular RNAs in Heart Tissue of Mice with Myocardial Infarction-Induced Heart Failure. Cell Physiol Biochem 2016;39:205-216.

21 Zhang T, Tian F, Wang J, Jing J, Zhou SS, Chen YD: Atherosclerosis-Associated Endothelial Cell Apoptosis by MiR-429-Mediated Down Regulation of Bcl-2. Cell Physiol Biochem 2015;37:1421-1430.

22 Zhang T, Tian F, Wang J, Jing J, Zhou SS, Chen YD: Endothelial Cell Autophagy in Atherosclerosis is Regulated by miR-30-Mediated Translational Control of ATG6. Cell Physiol Biochem 2015;37:1369-1378.

23 Li S, Fan Q, He S, Tang T, Liao Y, Xie J: MicroRNA-21 negatively regulates Treg cells through a TGF- $\beta 1 /$ Smadindependent pathway in patients with coronary heart disease. Cell Physiol Biochem 2015;37:866-878.

24 Yang Y, Yang L, Liang X, Zhu G: MicroRNA-155 Promotes Atherosclerosis Inflammation via Targeting SOCS1. Cell Physiol Biochem 2015;36:1371-1381.

-25 Suárez Y, Fernándezhernando C, Pober JS, Sessa WC: Dicer dependent microRNAs regulate gene expression and functions in human endothelial cells. Circ Res 2007;100:1164-1173.

-26 Kuehbacher A: Role of Dicer and Drosha for endothelial microRNA expression and angiogenesis. Circ Res 2007;101:59-68.

27 Nazari-Jahantigh M, Wei Y, Schober A: The role of microRNAs in arterial remodelling. Thromb Haemost 2012;107:611-618.

28 Zuo K, Zhi K, Zhang X, Lu C, Wang S, Li M, He B: A dysregulated microRNA-26a/EphA2 axis impairs endothelial progenitor cell function via the p38 MAPK/VEGF pathway. Cell Physiol Biochem 2015;35:477488.

29 Springer TA: Adhesion receptors of the immune system. Nature 1990;346:425-434.

30 Walton KW, Williamson N, Johnson AG: The pathogenesis of atherosclerosis of the mitral and aortic valves. J Pathol 1970;101:205-220.

-31 Price DT, Loscalzo J: Cellular adhesion molecules and atherogenesis. Am J Med 1999;107:85-97.

32 Cybulsky MI, Jr GM: Endothelial expression of a mononuclear leukocyte adhesion molecule during atherogenesis. Science 1991;251:788-791.

-33 Davies MJ, Gordon JL, Gearing AJH, Pigott R, Woolf N, Katz D, Kyriakopoulos A: The expression of the adhesion molecules ICAM-1, VCAM-1, PECAM, and E-selectin in human atherosclerosis. J Pathol 1993;171:223-229.

34 Mulvihill NT, Foley B, Crean P, Walsh M: Prediction of cardiovascular risk using soluble cell adhesion molecules. Eur Heart J 2002;23:1569-1574.

- 35 Stehouwer CDA, Henry RMA, Ferreira I: Arterial stiffness in diabetes and the metabolic syndrome: a pathway to cardiovascular disease. Diabetologia 2008;51:527-539.

-36 Na L, Wu X, Feng R, Li J, Han T, Lin L, Lan L, Yang C, Li Y, Sun C: The Harbin Cohort Study on Diet, Nutrition and Chronic Non-communicable Diseases: study design and baseline characteristics. PLoS One 2015;10:e0122598.

- 37 Lu H, Hao L, Li S, Lin S, Lin L, Chen Y, Cui H, Zi T, Xia C, Na L: Elevated circulating stearic acid leads to a major lipotoxic effect on mouse pancreatic beta cells in hyperlipidaemia via a miR-34a-5p-mediated PERK/ p53-dependent pathway. Diabetologia 2016;59:1247-1257.

- 38 Li J, Ma H, Na L, Jiang S, Lv L, Li G, Zhang W, Na G, Li Y, Sun C: Increased hemoglobin A1c threshold for prediabetes remarkably improving the agreement between $\mathrm{A} 1 \mathrm{c}$ and oral glucose tolerance test criteria in obese population. J Clin Endocrinol Metab 2015;100:1997-2005.

-39 Ross R: Atherosclerosis—an inflammatory disease. N Engl J Med 1999;340:115-126.

-40 van Popele NM, Grobbee DE, Bots ML, Asmar R, Topouchian J, Reneman RS, Hoeks AP, van der Kuip DA, Hofman A, Witteman JC: Association between arterial stiffness and atherosclerosis: the Rotterdam Study. Stroke 2001;32:454-460.

41 Taddei S, Virdis A, Mattei P, Ghiadoni L, Gennari A, Fasolo CB, Sudano I, Salvetti A: Aging and endothelial function in normotensive subjects and patients with essential hypertension. Circulation 1995;91:19811987.

42 Urbich C, Kuehbacher A, Dimmeler S: Role of microRNAs in vascular diseases, inflammation, and angiogenesis. Cardiovasc Res 2008;79:581-588.

43 Loyer X, Potteaux S, Vion AC, Guérin CL, Boulkroun S, Rautou PE, Ramkhelawon B, Esposito B, Dalloz M, Paul JL: Inhibition of microRNA-92a prevents endothelial dysfunction and atherosclerosis in mice. Circ Res 2014;114:434-443. 


\section{Cellular Physiology Cell Physiol Biochem 2017;41:2183-2193 \begin{tabular}{l|l} 
DOI: 10.1159/000475576 & $\begin{array}{l}\text { O 2017 The Author(s). Published by S. Karger AG, Basel } \\
\text { www.karger.com/cpb }\end{array}$ \\
\hline
\end{tabular} \\ Deng et al.: miR-1185 Modulates Arterial Stiffness}

-44 Liao YC, Wang YS, Hsi E, Chang MH, You YZ, Juo SH: MicroRNA-765 influences arterial stiffness through modulating apelin expression. Mol Cell Endocrinol 2015;411:11-19.

45 Freedman JE, Ercan B, Morin KM, Liu CT, Tamer L, Ayaz L, Kanadasi M, Cicek D, Seyhan AI, Akilli RE: The distribution of circulating microRNA and their relation to coronary disease. F1000Res 2012;1:50.

46 Deanfield JE, Halcox JP, Rabelink TJ: Endothelial function and dysfunction: testing and clinical relevance. Circulation 2007;115:1285-1295.

47 Zieman SJ, Melenovsky V, Kass DA: Mechanisms, pathophysiology, and therapy of arterial stiffness. Arterioscler Thromb Vasc Biol 2005;25:932-943.

-48 Jacob MP: Extracellular matrix remodeling and matrix metalloproteinases in the vascular wall during aging and in pathological conditions. Biomed pharmacother 2003;57:195-202.

49 Galis ZS, Khatri JJ: Matrix metalloproteinases in vascular remodeling and atherogenesis: the good, the bad, and the ugly. Circ Res 2002;90:251-262.

-50 Igarashi J, Michel T: Sphingosine-1-phosphate and modulation of vascular tone. Cardiovasc Res 2009;82:212-220.

-51 Brasier AR, Recinos A, Eledrisi MS: Vascular Inflammation and the Renin-Angiotensin System. Arterioscler Thromb Vasc Biol 2002;22:1257-1266.

52 Seal JB, Gewertz BL: Vascular dysfunction in ischemia-reperfusion injury. Ann Vasc Surg 2005;19:572-584.

53 Doran AC, Meller N, Mcnamara CA: Role of smooth muscle cells in the initiation and early progression of atherosclerosis. Arterioscler Thromb Vasc Biol 2008;28:812-819.

-54 Petersen EJ, Miyoshi T, Yuan Z, Hirohata S, Li JZ, Shi W, Angle JF: siRNA silencing reveals role of vascular cell adhesion molecule-1 in vascular smooth muscle cell migration. Atherosclerosis 2008;198:301-306.

-55 Collins T, Read MA, Neish AS, Whitley MZ, Thanos D, Maniatis T: Transcriptional regulation of endothelial cell adhesion molecules: NF-kappa B and cytokine-inducible enhancers. FASEB J 1995;9:899-909.

-56 Croft D, Mcintyre P, Wibulswas A, Kramer I: Sustained Elevated Levels of VCAM-1 in Cultured Fibroblastlike Synoviocytes Can Be Achieved by TNF- $\alpha$ in Combination with Either IL-4 or IL-13 through Increased mRNA Stability. Am J Pathol 1999;154:1149-1158.

57 Pietersma A, Tilly BC, Gaestel M, De JN, Lee JC, Koster JF, Sluiter W: p38 mitogen activated protein kinase regulates endothelial VCAM-1 expression at the post-transcriptional level. Biochem Biophys Res Commun 1997;230:44-48. 